\title{
The Body, Thought Experiments, and Phenomenology*
}

\section{Yiftach J. H. Fehige (Toronto, Canada) \& Harald Wiltsche (Graz, Austria/Toronto, Canada)}

Our explorative contribution to the ongoing discussion of thought experiments might already surprise by its very title, and this is for at least two reasons. First, isn't the topic of thought experiments exclusively part of the domain of analytic philosophy? Second, isn't the point of thought experimentation to leave the body behind while withdrawing into the laboratory of the mind? We are inclined to answer negatively to both questions.

While endorsing the majority view that skepticism about thought experiments is not well justified, in what follows, we attempt to show that there is a kind of "bodiliness" missing from current accounts of thought experiments. That is, we will suggest a phenomenological addition to the literature. First we will contextualize our claim that the importance of the body in thought experiments has been widely underestimated. Then we will discuss David Gooding's work, which contains the only explicit recognition of the importance of the body to understanding thought experiments. Finally, we will introduce a phenomenological perspective of the body, which will give us the opportunity to sketch the power and promise of a phenomenological approach to thought experiments. ${ }^{1}$

\section{The Missing Body from 1811 to 2011}

The practice of thought experiments is probably as old as the human mind. Thought experiments have been recorded since the times of ancient Greek philosophy (see Ierodiakonou 2005). They became a subject matter of philosophical reflection in the $18^{\text {th }}$ century. It all began with Kant (see Kühne 2005 , 95-105), not with Ernst Mach as it is still commonly believed. From the beginning, thought experiments have been widely perceived as an instance of bodiless cognition. Almost nobody has argued to the contrary.

Kant refers to philosophical thought experiments as "experiments of pure reason" (see Kant 1998, 112[BXXI]). Kant's experiments of pure reason test transcendental principles by demonstrating "that experience would assume a fundamentally different form if the tested [transcendental, Y.F./H.W] principle were false" (see Kalin 1972, 322-323). These tests require a drastic disconnect from the kind of experience that originates from embodied existence. Hans Christian Ørsted, who actually introduced the technical term "thought experiment" in its Danish version Tankeexperiment (see Ørsted 1920[1811], 172), refers to Kant's Metaphysical Foundations of Natural Science as a treasure trove of scientific thought experiments. According to Ørsted, thought experiments in science "set our mind itself in creative activity in order to develop lively and vigorous knowledge" (Ørsted 1998[1811], 295). There is no mentioning that the creativity under consideration were embodied.

In this respect the situation did not change when many decades later after Kant and Ørsted, in the 1990s the debate between James R. Brown and John D. Norton arose (see Brown 2011; Norton 1996). The former introduced a Platonic account of thought experiments. The latter countered with the claim that thought experiments are epistemologically dispensable, because they are just arguments. But

\footnotetext{
This contribution is fully collaborative. Many thanks to Jim Brown, Melanie Frappier, Letitia Meynell, and Mike Stuart for helpful feedback to an earlier draft of this paper.

1 It should be noted right from the outset that, in a similar sense in which there is not just one analytic movement, but rather a number of individuals working in roughly the same philosophical spirit, there is not just one unified phenomenological approach. This justifies our talk of a "phenomenological approach", although we are actually considering only the work of Edmund Husserl and Hermann Schmitz. Also, we cannot emphasize enough that we are aware of the significant differences between Husserl and Schmitz as far as phenomenological method is concerned. See Schmitz 19641980, vol. III, Part 1, 1-7. For a short summary of Schmitz' criticisms of Husserl see Schmitz 1980, 15. We believe that Schmitz overplays the differences, and don't think that the differences between his and Husserl's phenomenology have any relevance for the way in which we are about to use their respective phenomenological insights into the nature of the body.
} 
both share the view that our bodies matter not much in thought experiments. Brown highlights an intellectual perception with the mind's eye. The body has nothing of significance to contribute here. The same is true for Norton who accounts for thought experiments in terms of abstract propositional reasoning.

Currently, almost nobody shares Brown's Platonism, and only few sympathize with Norton's idea that we can reduce thought experimentation to the performance of propositional lines of reasoning. But among the many who disagree with Brown and Norton, Gooding has probably been the only author to point out explicitly the significance of embodiment for thought experimentation. The biggest challenge in substantiating this claim is to spell out what exactly embodiment means. The idea of embodied cognition has been understood in many different ways. In fact, part of what follows is to indicate the difference between embodiment à la Gooding and a phenomenological approach to the bodiliness involved in thought experiments.

We think Gooding is right when claiming that the body matters in thought experiments. Yet, we are reluctant to accept the kind of naturalism that informs his views. The main reason for our reluctance is not the many philosophical problems pertaining to naturalism (see, e.g., recently Sklar 2010). It is rather the fact that a naturalistic approach to the body is not without an alternative, and that a critical discussion of this alternative has yet to be carried out. We are gesturing towards a phenomenological approach to the body, and we do this is for at least three reasons. First, in the literature the opinion has been expressed repeatedly that one of the central methods in phenomenology, namely the eidetic reduction, is an instance of thought experimenting (see Froese and Gallagher 2010; Lotz 2007, 9; Mohanty 1991; Myers 1986, 109). Second, when analytic philosophy and phenomenology come into contact, especially in the area of the mind-body problem, thought experimenting seems to be an ideal means to encourage more constructive interaction between the two schools. That is, while thought experiments are frequently used as a tool of analytic philosophers, the method of phenomenology seems to make available a more direct familiarity with the mind (as we will show below), and this is something by which analytic philosophy could profit. Third, the bodily component of thought experimentation suffers from a complete lack of philosophical attention. The development of a phenomenological approach to this component of thought experimenting would be a useful and viable task, because it was phenomenology that re-appropriated the body as a subject matter of philosophy (see e.g. Hammer 1974, 81; Welton 1999). The German philosopher Hermann Schmitz developed a system of philosophy out of a phenomenology of the body (see Schmitz 1964-1980). His central claim is that all we are is body, and it is the body that holds the key to understanding ourselves and everything else there is. Since, so far, Schmitz' comprehensive philosophy of the body is rather underrepresented in the Anglophone debate, we are going to include some of his work in the following discussion of the bodily component of thought experimenting in order to demonstrate the feasibility of a phenomenological approach to thought experiments. First, however, we will discuss Gooding's case for a philosophy of science that is guided by the principle of what he calls "hands over heads". This principle is central in Gooding's theory of the bodily dimension of thought experiments. The principal aim of the next section is to have a look at this theory in order to motivate our search for a phenomenological approach to thought experiments.

\section{"Hands Over Heads": Gooding on Thought Experiments}

Despite his pursuit of "naturalistic approaches to science" (Gooding 1992, 51), Gooding has argued that "thought experiments are useful, powerful, elegant and important." (Gooding 1993, 280) To rationalists like Alexandre Koyré or Brown, he has conceded "the importance of thought experiments in generating new science." (Gooding 1992, 69) Yet, while they are indeed "conducted entirely within the world of representations", Gooding believes that thought experiments wrongly suggest "that representations are self sufficient." (Gooding 1990, 203) In general, Gooding argues, to play "down the empirical and material aspect of scientific thinking in favor of the march of ideas and arguments" 
(Gooding 1990, 203) is "just bad philosophy." It is bad philosophy because it follows the principle of "heads over hands." This principle, claims Gooding, has already misled the study of science for too long. We need to do better. We need to get the body into the picture. Hands come first, then the head. This is also true for the scientific practice of thought experimentation.

According to Gooding, the crucial question about thought experiments is as follows: "how do scientists go from the actual to the possible, on to the impossible, and return to an actual world altered by that journey?" (Gooding 1990, 204) Like Mach (1897, 1905), Sorensen (1992) and Buzzoni (2008)2, Gooding has defended what we call experimentalism in response to that question. What this means becomes clear when he says, for example: "Thought experiments are conducted in mental laboratories but they do not thereby cease to be experiments." (Gooding 1993, 281) This is experimentalism in a nutshell, and one way to account for the apparent cognitive efficacy of thought experiments. The basic idea of experimentalism is simple: If we take real-world experiments to be of cognitive value due to their experimental character, then we have sufficient reason to do the same with respect to thought experiments, since the difference between the two is less than often thought.

Mach has argued for experimentalism by drawing attention to the fact that real-world experiments and thought experiments alike employ the methodological principle of variation (see Kujundzic, 1998). Roy A. Sorensen has argued for experimentalism in terms of logical regimens that are common to both thought experiments and real-world experiments in relating an imagined scenario to a target theory. Marco Buzzoni follows Kant's notion of experiment, and argues that the experimental character is a matter of putting a question to nature, and this in a way that it is specific with respect to realizable technical operations. He thereby puts thought experiments and real-world experiments into a (non-Hegelian) dialectical relationship: "...granted that no thought experiment can be a whole experiment, it is also the case that without thought experiments there could be no experiments." (Buzzoni 2008, 96)

In Gooding's case there is no (non-Hegelian) dialectical, but a much weaker relationship between real-world experiments and thought experiments. Gooding is closer to Mach and Sorensen in this respect. But he is closer to Buzzoni in that he emphasizes the relationship between thinking and doing. The relation between thought experiments and real world experiments is a function of "the interdependence of thinking and doing." (Gooding 1990, 204) The experimental character is defined in terms of testing the "practicability of doing something in just the way required by the theories in the world as represented by theory. In other words, theory is criticized through the practices that link it to those aspects of the world that it purports to be about." (Gooding 1993, 280) Gooding's version of experimentalism clearly articulates his basic conviction that doing, and in this sense the body, matters for cognition. We are encouraged to consider visual perception. An "example of the importance of doing to seeing is Sidney Bradford. Blind from infancy, his sight was restored by corneal grafts after fifty years. At first Bradford could see only those objects he had already explored by touch..." (Gooding 1992, 45) Examples like this reassure Gooding that a careful analysis of the bodily component of cognition enables philosophers of science to see most effectively that the "assumption about the priority of head over hands" (Gooding 1992, 47) is a myth. What matters in each experiment, argues Gooding, is a relation between actual and possible worlds, and it is the body that connects the two realms. But the importance of the body can come into view only if philosophers of science realize that textbook experiments are the result of a substantial "editing out much of what went into achieving the results." (Gooding 1992, 46) We have to bring into focus the locality and situatedness of experimental science, Gooding claims. Then we will come to realize that every experiment operates at the intersection of the two worlds of the actual and the possible, and that it is the body that makes possible real-world experiments and thought experiments alike.

2 It probably should be mentioned that there are significant differences between these four experimentalist approaches to thought experiments. See Buzzoni (2008), 74-80. But they are irrelevant for our considerations. 
Gooding's approach to thought experiments might come as a surprise if one is inclined to believe that it is especially the detachment from the body that allows for thought experimentation. Gooding is ware of this. Hinting at Quinean language-centrism, Gooding states that thought experimenting is a "sort of experimentation that becomes possible when semantic ascent is largely complete." (Gooding 1990, 203) Yet, at the same time, he argues that embodiment makes the semantic ascent (and thus thought experiments) possible in the first place. Bodies do this in the following two ways:

First, for those encountering a thought experiment, mental participation in the world of the thought experiment is only possible by the thought experiment's narrative, because it initiates a process of constructing less familiar features through familiar ones, and this process is a function of embodiment. By means of seeing, feeling, or interacting with objects in the world of the thought experiment, unfamiliar features can manifest in a plausible manner: "I contend that T[hought]experimenters must have learned enough about a world of one kind (through vision, touch and hearing) to access other, less familiar worlds. The very possibility of participating depends on familiarity with ordinary perceptual experience of any kind. T[hought]-experimenters must be at home in their bodies." (Gooding 1993, 285)

Second, for those developing a thought experiment, there must be a direct appeal to ordinary properties of objects. Otherwise the resulting thought experiment's narrative will not establish an intelligible, sensory framework for understanding the procedures and phenomena that make up the experiment in question. We are only familiar with these properties because of our embodiment. No embodiment, no experiment of any kind. This is to say that every experiment reflects a creative play between the familiar and the unfamiliar. This crucial aspect in the development of thought experiments comes to light when we remove those layers of the experiment-narratives that we find in textbooks. They conceal four important features of observation and experiment: 1. The non-linearity of observation and experiment. 2. The importance of human agency in the manipulation and transformation of real and imaginary objects. 3. The interaction of concepts, precepts and objects. 4. The creativity due to uncertainty. (Gooding 1992, 47) Concealment of these features of experimental practice in experiment-narratives is an effect of six different types of narrative reconstruction (Gooding 1992, 50). Each type involves (i) different activities, (ii) different kinds of narration, and (iii) the achievement of different ends. To illustrate the basic idea, let us look at an example of the type of narrative reconstruction that Gooding calls cognitive reconstruction: temporal ordering is imposed by the scientist on his or her perceptions in order to make sense of them in relation to the uniform forward time progression of an external physical reality. What happens during cognitive reconstruction in this case is that the scientist assimilates the non-linear time of conscious experience, with the linear time progression of an external physical reality. Such processes of cognitive reconstruction and other types of narrative reconstruction by scientists are well documented in their notebooks, sketches and letters, Gooding declares. They involve activities like the construction of a perceived object, the creation of interaction patterns with other than these objects, and a good amount of reasoning to relate observation and theory. Narrative reconstruction aims to represent and communicate the observed while implementing it into an argument in favor of or against the relevant pieces of theory.

\section{"Grounding" Gooding's Experimentalism}

Experimentalists need to ground the experimental character that unites real-world experiments and thought experiments, otherwise it remains unclear where the epistemic power of experiments comes from. Mach $(1897,1905)$ and Sorensen (1992) ground their experimentalist accounts with a kind of evolutionary theory, which only in Sorensen's case is clearly of a Darwinian kind. Buzzoni (2008), on the other hand, appeals to a certain tradition of understanding the Kantian a priori, and tells us a story about the indispensable role that the transcendental nature of the mind plays in conjunction with operationalized ways of obtaining experience in experimentation outside of the mind. To play on 
Gooding's metaphor, Buzzoni argues for "head and hands" in contrast to Mach's and Sorensen's "head over hands." Gooding commits himself to "hands over head."

What grounds this priority of hands over head is a reference to human agency, and some related empirical and material considerations. If we understand human agency then we understand experimentation, be it in the head or in the real world. Understanding human agency in turn is a function of understanding procedures. Procedures are "sequences of acts or operations whose inferential structure we do not yet know. The term procedural connotes know-how." (Gooding 1992, 53) What is basic is skill, not conceptual knowledge or the intentionality of acts: "...rationales for actions often emerge as understanding develops or as an account unfolds." (Gooding 1992, 53) In mapping experimental processes in real time, he therefore "represents human agency directly, by a line, against which an active verb is presented." (Gooding 1992, 60) This is to separate the material things that are subject to this agency, from related choices and decisions, and also from related conceptual changes. Experimentation is mainly a function of embodiment, because human agency is bodily. Gooding's body is the necessary condition for intervening with the world, and it instantiates a relatively autonomous parameter in the process of experimental practice. The body is the source of agency, which in turn enables the scientist to move from one event or object to the next. This is the same agency which makes possible the scientific production of potentially novel events and objects, which helps to drive scientific research.

While Gooding's consideration certainly makes a note-worthy case for "hands over heads", we are wondering if the body is well perceived in his account of thought experiments. From a phenomenological perspective a number of serious problems can be raised.

\section{"Grounding" Phenomenology - The Epoché}

From a phenomenological point of view, some of Gooding's claims, especially with respect to the role of the body, may sound familiar. Phenomenologists ranging from classical thinkers such as Edmund Husserl, Maurice Merleau-Ponty, Jean-Paul Sartre or Aaron Gurwitsch to contemporary scholars like Samuel Todes, Maxine Sheets-Johnstone or Hermann Schmitz have emphasized that the body is a necessary condition of the possibility of any encounter with the natural world. Yet, the body of phenomenology is not identical with the one Gooding has in mind. In order to show this, we need first to say something about the general scope of phenomenological philosophy. Only then will it become clear where we see the potential in the phenomenological elucidation of the body to shed some additional light on the philosophical understanding of the bodily component of thought experiments.

As phenomenology is concerned with the reflective analysis of phenomena, it seeks to analyze the "how" of the different modes of experience and not their "what", i.e. their actual content. With regard to this task, phenomenology, as it was developed by Husserl, draws upon Franz Brentano and the notion of intentionality. Unlike in Gooding, intentionality comes first in terms of philosophical method because it is taken to be the crucial characteristic of consciousness. To say that consciousness is intentional is to recognize that there is an essential correlation between an act of consciousness (the noetic aspect such as perceiving, knowing, imagining, etc.) and an object as it is meant and intended (the noematic aspect, i.e. the object as perceived, the object as known, the object as imagined, etc.). Phenomenology, then, deals with the systematic analysis of various noetic-noematic correlationstructures.

In spelling out the intentional correlations between subject and world, phenomenology pursues a traditional epistemological goal: phenomenologists seek to identify those conditions that make our thought and experience of natural objects possible. Yet, as Husserl has stressed in detail, this kind of reflective analysis is impossible without certain methodological precautions (e.g. Husserl 1983, chapter 4). Husserl's reasoning goes as follows: usually, when we are directed towards the world within the 
natural attitude ${ }^{3}$, we implicitly accept a number of unquestioned presuppositions. Most fundamentally, we implicitly presuppose that there exists a world which consists of a multitude of objects and that these objects can be investigated by means of empirical methods. This fundamental presupposition is constitutive for any empirical investigation, be it scientific or extra-scientific in nature. However, if the validity of our empirical claims depends on this fundamental presupposition, it also follows that we cannot rely on the findings of our empirical investigations when asking for the conditions that make our thought and experience of natural objects possible. According to Husserl, the basic failure of naturalistic philosophy is that it assumes that empirical knowledge is possible in order to explain the possibility of empirical knowledge. Husserl sought to avoid this vicious circularity by introducing the method of the phenomenological epoché (see Moran 2008).

To perform the phenomenological epoché is to abstain from all those presuppositions which we usually take for granted and which in sum make up the natural attitude. However, it is important to note that in performing the epoché we do not actively doubt any of these presuppositions. The epoché is merely methodological in nature; it is primarily designed to identify the conditions of the possibility of natural thought and experience without falling prey to vicious circularities. Yet, by embracing this methodological tool, phenomenologists also commit themselves to an approach which is both reflective and descriptive. The aim of phenomenological analysis is not to construct theories in order to answer epistemological questions. In performing the epoché, phenomenologists strive for a presuppositionless description of phenomena and for the reflective exposure of those structures which are necessary for our different forms of natural encounters with the world.

With these methodological considerations in mind, we are now in a position to contrast Gooding's views about the body with those of phenomenology.

\section{On the Phenomenological Body}

As we have seen, Gooding advances the body within a naturalistic framework. This is to say that whatever role the body might be playing in thought experiments, any characterization of this role will be empirical in nature. From a naturalistic perspective in which the totality of reality is equivalent with the physical realm, the human body is just another (albeit highly complex) spatiotemporal object. Now, the point of phenomenology certainly is not to say that this view is altogether mistaken. It would be quite peculiar to deny that the human body is also a physical thing which can be investigated by empirical means. And it would be just as dogmatic to deny that empirical findings about the interactions between embodied actors and the world are in principle futile if a philosophical elucidation of thought experiments is at stake. However, what phenomenologists are eager to emphasize is that there are aspects of the human body which cannot, in principle, be addressed by empirical means. It is especially the constitutive role that the body plays in our natural encounters with the world which seem to fall outside the naturalistic picture. Yet, it is exactly this constitutive role which, on a phenomenological view, is of utmost importance for our understanding of the relations between subject and the world.

One way to show that the body plays such a constitutive role is to take a closer phenomenological look at how we perceive spatiotemporal objects. These objects are, as Husserl and others have emphasized at numerous occasions, always and necessarily given perspectively. This is to say that spatiotemporal objects can never be given adequately, i.e. that a particular intention towards a spatiotemporal object can never specify every aspect of the object in question. At any point in time, a spatiotemporal object has, for instance, a back side which is momentarily hidden due to the subject's vantage point. This fact, however, has severe implications for the way the phenomenon of perception is

3 According to Husserl, the natural attitude is the attitude within which we stand before we take up a reflective stance towards the "How" of our world-involvement. This is to say that it is only by means of philosophical reflection that we are able to unveil those presuppositions which underlie our scientific and extra-scientific interactions with the world (see, e.g., Husserl 1983, § 30). 
to be understood: That spatiotemporal objects are always given perspectively also means that every perspectival appearance of an object does not only presuppose something which appears, but also someone for whom the perspectival appearance appears (Zahavi 1994, 65). Or in other words, since spatiotemporal objects always appear from a certain distance and from a certain angle, their givenness presupposes a "zero-point of orientation" (e.g. Husserl 1989, 166) from which the perception and interaction with spatiotemporal objects occurs. This "zero-point" is, according to phenomenology, the human body, which serves as the irreducible center of spatial orientation. It is only due to its embodiment in space that the subject is able to perceive its natural surroundings from a first-personperspective.

Yet, being the "zero-point of orientation" is by no means the only constitutive function the body plays in the course of our natural perception. The constitution of perceptual reality is also dependent on the experience of bodily movements or, to use Husserl's original term, on kinaesthetic experience. With regard to this aspect, a possible argument goes as follows: ${ }^{4}$ As we have seen, intentions towards spatiotemporal objects always have "excess content" over what is actually given in perceptual experience. This is to say that we are usually intentionally directed towards spatiotemporal objects in their unity, even though only perspectival appearances of these objects are actually given. However, this discrepancy between what is perceptually given and what is picked out by the intention raises the question of how the meaning-content of "spatiotemporal objects in their unity" is constituted. How are we able to be intentionally directed towards, say, a table, if a series of perspectival profiles is all that is actually given? How do we know that changing appearances are appearances of one and the same thing?

The answer, from a phenomenological viewpoint, is to say that every act towards a spatiotemporal object is related to a manifold of potential acts which would complete what is left indeterminate about the object as it is intended in a given act. Yet, the unity between these potential acts is dependent on a specific "I can" (e.g. Husserl 1968, 391), i.e. on a non-thematic knowledge about the potentiality of bodily movement. According to Husserl, any actual perception refers to a manifold of "perceptions that we could have, if we actively directed the course of perception otherwise: if, for example, we turned our eyes that way instead of this, or if we were to step forward or to one side, and so forth" (Husserl 1960, 44). Thus, the body is not only the fixed center in relation to which perspectively given objects and primordial space unfolds itself; it is also the medium by means of which the intentional directedness towards spatiotemporal objects becomes possible.

As we have seen so far, phenomenology regards the body as a necessary condition of the possibility of the perception and interaction with the natural world. The body is not merely a vehicle which allows a disembodied subject to navigate through its physical surroundings. Since the intentional directedness towards spatiotemporal objects and even our most basic concept of primordial space always presupposes bodily situatedness, the idea of a disembodied subject turns out to be highly questionable, and thus Gooding's dissociation of the body in the sense of one physical object among others from the lived body in his reconstruction of the bodily dimension of thought experimentation becomes problematic. Phenomenologically construed, the body and the subject are inextricably intertwined. Gooding's body is a problematic abstraction and runs the risk of underestimating the bodily character of the hands in his notion of "hands over heads."

However, the just mentioned difference is by no means the only discrepancy between Gooding's view of the body and a phenomenological account. Let us recall the methodological considerations of the previous section in order to see another important point: If it is true that embodiment is the condition of the possibility of natural thought and experience, it also follows that the

4 More radical ways to understand the role of kinaesthesis were, for instance, formulated by Maxine Sheets-Johnstone (2000). On her view, the bodily ability to move oneself is the precondition not only for human agency and the acquisition of skills, but also for any intentional contact with our worldly surroundings. 
phenomenological notion of the body cannot be equivalent to the natural notion of physical bodies or things. Since the constitution of the latter presupposes the former, we have to distinguish sharply between lived bodies (in German: Leiber) and physical bodies or things (in German: Körper). The former is phenomenologically described after the epoché; the latter described with respect to the various scientific or extra-scientific natural attitudes. As we saw earlier, phenomenologists do not deny that the lived body can be treated as a physical thing amongst others. The possibility to do so, however, depends on a basic acquaintance with the very concepts of natural "thinghood" and natural (i.e. primordial) space which in turn presupposes the constitutional capacities of an embodied subject. Or, as Dan Zahavi has put it: "My original and immediate relation to my body is not an experience of the body as an object. Quite to the contrary, we are here dealing with a self-objectivation [sic], which just like every other perceptual experience is dependent upon and made possible by the unthematized cofunctioning body-experience." (Zahavi 1994, 69) Thus, from a phenomenological perspective, Gooding's body has to be supplemented by a deeper, further-reaching conception of the lived body.

In order to indicate the sense in which the phenomenological alternative to Gooding's exclusive focus on the physical body could affect the interpretation of thought experiments, a concrete example might help. Let us therefore turn to Newton's well-known "bucket experiment".

\section{Newton's Bucket}

"Newton's bucket" can be found in Newton's Principia (Newton 2002, 741-742). It "is one of the most celebrated and notorious examples in the history of thought experiments." (Brown 2011, 7) One of the reasons why it is so fascinating (and ideal for the present discussion), is the ease with which it employs very familiar objects and procedures in order to "show the existence of absolute space" (Brown 2011, 7). Absolute space is something quite exotic from the perspective of familiar objects and procedures.

To refresh our memory, the thought experiment goes as follows. First, you imagine yourself filling a bucket halfway with water, and suspending it from some fixed point with a rope. You twist the rope more and more by rotating the bucket. There are now three distinct stages to observe. In the first, after the rope has taken all the twisting that it can take but before you have let go of the bucket, there is no relative motion between the water and the bucket. The level of the water is flat. In the second stage, you release the bucket and notice that there is now relative motion between the water and the bucket as the bucket spins while the water remains stationary, still flat in the bucket. In the third stage, there is once again no relative motion between the water and the bucket because both are spinning at equal velocities, but this time the level of the water is concave as it has crept up the side of the bucket. This is all very familiar, yet we are now presented with something that is not: it seems we must posit the existence of something to explain the difference between the first and the third stages. In each, there is no relative motion between the bucket and the water, but there is a difference in the curvature of the water-level. Since everything else has been abstracted away, there is nothing else in relation to which the bucket could be spinning, save absolute space. You can come to the same conclusion by considering another situation in which two rocks are attached by a rope. Far away from gravity and any point of reference, you notice that there is tension in the cord. Again, you seem forced to admit the existence of something in relation to which the system is rotating, since the only way to explain this tension in the absence of a detectable relative motion is revolution. In each case the imagined rotation drives you to accept the idea that absolute space is the only explanation for this phenomenon established in the "laboratory of the mind."

According to Hans Reichenbach, "only by passing through a state of absolutism in the theory of space [...] we have been lead to the deeper insights we have today." (Reichenbach 1958, 212) To uphold a "hands over heads" approach to account for thought experiments as important as Newton's bucket experiment, one needs to show that thought experiments in general and Newton's bucket experiment in particular have a life of their own in the following sense. If a thought experiment is employed in the context of two contradictory theories $\left(T_{1}\right.$ and $\left.T_{2}\right)$, where a version of the thought 
experiment, call it $\mathrm{V}_{1}$, supports $\mathrm{T}_{1}$, and a modified version of the thought experiment, call it $\mathrm{V}_{2}$, supports $\mathrm{T}_{2}$, we may say that the thought experiment has a life of its own if and only if the evidential force of $\mathrm{V}_{1}$ remains partly intact despite a conscious acceptance of $\mathrm{T}_{2}$ in light of $\mathrm{V}_{2}$, and this evidential force cannot simply be reduced to a theoretical mistake that is accessible only from $\mathrm{T}_{2}$. From the perspective of Gooding's account, this is certainly the case when comparing Ernst Mach's version of the bucket thought experiment, $V_{2}$, (see for a further discussion Kühne 2005, 191-202) with Newton's original version of it, $\mathrm{V}_{1}$, the former being employed in favor of a relativistic conception of physical space $\left(\mathrm{T}_{2}\right)$. Hence Gooding's approach succeeds in this respect. Newton's original version of the bucket thought experiment retains evidential force despite a conscious acceptance of relativistic physics, and this is a function of the familiarity of the involved objects and procedures as well as the generally accepted method of idealization in physics, which allowed Newton to work with an empty universe. Without going into further details of a comparison between Newton and Mach's version of the bucket thought experiment, our point is to highlight how a phenomenological approach to thought experimenting can complement the emerging picture of the relative autonomy of the "laboratory of the mind" in at least two important respects. First, we will suggest an account of the origin of absolute space from the perspective of a phenomenology of a body. Then we will suggest several ways to characterize the quality of thought experiments on space from a phenomenological perspective, which are not meant to be exclusive, of course, but which can serve to complement other perspectives.

\section{On Absolute Space}

We will now turn to the first point: how the notion of absolute space may be introduced in a thought experiment from a phenomenological perspective. In 1921 the British physicist Alfred A. Robb expressed how strongly repelled he was by the "idea that events could be simultaneous to one person and not simultaneous to another; which was one of Einstein's chief contentions. [...] If two physicists $A$ and $B$ agree to discuss a physical experiment, their agreement implies that they admit, in some sense, a common world in which the experiment is supposed to take place." (Robb 1921, v-vi) Given Gooding's characterization of experiments as being located at the intersection of the actual and the possible, Robb's claim that every conceivable experiment presupposes the idea of a "common world" certainly makes sense. Phenomenologists would say that the very foundation of this "common world" is the domain of what we would like to call the possibilities of the lived body. On a phenomenological view, these possibilities are not only irreducible to metaphysical, logical, epistemological and nomological possibilities, they are also crucial for the philosophical understanding of any thought experiment in physics generally, and those about space in particular. This is because, phenomenologically construed, the domain of the possibilities of the lived body is inextricably linked with the notion of primordial space on which all other (scientific and extra-scientific) conceptions of space are founded.

As we have just seen, phenomenology argues for a priority of the lived body, which implies a priority of primordial space. This is of utmost importance for the interpretation of thought experiments about space. To support such an assertion, we must make the following claim plausible: The possibility and quality of any thought experiment on space is (among other things) a function of (1) there being a space that is both prior and irreducible to scientific (i.e. mathematical and physical) conceptions of space, and (2) there being ways to account for the relationship between this space and other kinds of space. In order to establish (1) and (2), we want to supplement the methodological repertoire introduced above with some fundamental insights that can be found in Schmitz' phenomenology of the body.

\section{The Space of Vastness and The Absolute Locality of the Lived Body}

While Schmitz' work is almost entirely ignored, especially in the English-speaking world, we believe that his phenomenology of the body could lend considerable support to a philosophy of science that follows the principle of "hands over heads". Yet, we cannot do more here than to focus on one aspect 
of (thought) experiments on space, namely on its relation to the lived-body and to primordial space. In addition, we can only glimpse into Schmitz' extensive work on space (Schmitz 1964-1980, volume III, Part 1), not to mention its relationship to his overall philosophical system that is based on his comprehensive phenomenology of the body. ${ }^{5}$

According to Schmitz, by putting "head over hands", philosophy since Plato has committed a grave error. The discovery of the mind brought about the masking of the lived body (Schmitz 19641980, vol. II. Part 1, 441). This has caused a number of problems, including the reality of space. Only phenomenology is able to correct the unfortunate development of the last 2500 years, argues Schmitz. Very generally, space is most accurately described as a vastness (in German: Weite) that can be given purely or shaped to a certain form. Vastness is an Ur-phenomenon that cannot be fully explicated in the form of a definition (Schmitz 1984-1980, vol. III. Part 1, 7-10). Yet, it articulates itself in every kind of lived-bodily experience. This is because the lived body must be defined by a position that is absolute. Otherwise we are not able to accommodate experiences like those documented in reports of phantom limbs (Schmitz 1964-1980, vol. II. Part 1, 5-24). The space that corresponds to the lived body is therefore the space of vastness, which is unmeasurable (see Schmitz 1964-1980, vol. III. Part 1, 203208). The place of the lived body is absolute in retraction from vastness. In a nutshell, bodiliness is defined in terms of absolute location. But the lived bodiliness that gives meaning to a human life and everything there is, is a function of the relationship between vastness and narrowness (in German: Enge). Vastness and narrowness are the primordial poles of bodily existence (see Schmitz 1964-1980, vol. II. Part 1, 163, 213).

An example might help to illustrate the dynamics that is involved in any lived body as it originates from the simultaneous and counteracting tendencies towards vastness and narrowness. Let us assume that the tendency towards vastness and narrowness is in equilibrium in the bodies of two persons who engage in sexual intercourse. Schmitz describes the increasing arousal that eventually culminates in orgasms in terms of the dynamics as it emerges from the simultaneous and counteracting tendencies towards vastness and narrowness. He identifies three stages of "voluptuousness" (in German: Wollust) (see Schmitz 1964-1980, vol. II. Part 1, 220-223). What happens at a first stage is exemplified when we experience a breeze on a very hot summer day. The lived body begins to dissipate into small islands, something that is not possible while the lived body is still in the grip of the tendency to narrowness. At the second stage the two tendencies towards vastness and narrowness begin to counteract rhythmically. What happens at this stage can be experienced while having a swim, for example. Intermittently, the tendency towards narrowness can be dominant, although the tendency towards vastness predominates overall. At a third stage the competition between the two forces can be so strong that the two tendencies disconnect. That is what we experience in an orgasm. At this point the space of vastness comes to the fore in pure form (see Schmitz 1964-1980, vol. III. Part 1, 167-169).

Given Schmitz' phenomenology of the space of vastness, we would like to suggest the following: if there is anything that can be taken as a lived-bodily possibility to account for (thought) experiments on absolute space, then probably it is the space of vastness as it is primarily articulate in all bodily life insofar as bodiliness is defined in terms of absolute locatility. Familiar objects of relative locality in a physical space as well as the procedures involving them are secondary in terms of conditions of possibility. This is the point we would like to make against Gooding. Focusing on relative locality misses the domain of the possibilities of the lived body. It does not even get the body in its absolute locality in focus, not to mention the space of vastness that defines the lived body. A (thought)

5 Schmitz' work has defined the foundations of the Society for New Phenomenology (SNP), which is preparing an English translation of his System der Philosophie. In our view, this is long overdue as it most likely will open up new and original venues for a fruitful reception and critical discussion of his views, which are extensively substantiated in an exceptional manner. This is not to say that we would endorse all of Schmitz's views. On the contrary, we are aware of several significant shortcomings of his philosophy. However, none of them are significant enough to justify an ignorance of his work. For more information about the SNP see: http://www.gnp-online.de/index.php?id=15\&L=1. 
experiment on absolute space is, we suggest, the better the more it authentically preserves the phenomenon of the space of vastness as given in bodiliness. In this respect, Newton's bucket experiment is arguably a good one. But this is certainly not enough for a (thought) experiment on absolute space to be deemed successful on the whole as far as phenomenological criteria are concerned. In addition, given the unity of vastness and the fact that it underlies all kinds of space (see Schmitz 1964-1980, vol. III. Part 1, 193-203), the quality of a thought experiment on space depends on the way it respects the relationships between different ways of forming vastness, i.e. different kinds of space. We have not said much yet about these relationships but much of the work of Schmitz is dedicated to analyzing them. Most basic is the question, "What relates the different kinds of space?" According to Schmitz, it is directedness that matters for a phenomenological classification of different kinds of space and a phenomenological characterization of their relationship. The central idea is as follows.

\section{From Absolute Space to the Space of Physics}

We start with the space of vastness, which is the most basic kind of space. From here we develop the other kinds of space in terms of directedness by which the two counteracting tendencies towards vastness and narrowness are related (see Schmitz 1964-1980, vol. II. Part 1, 98, 163, 213). When experiencing climate, for example, we experience the space of vastness, and can express this space as a subject in utterances like "It is humid." Sometimes we can experience this space also when perceiving a sound, like that of a screeching circular saw (Schmitz 1964-1980, vol. III. Part 1, 47-54). But when direction begins to mediate the retraction of the lived body from vastness (Schmitz 1964-1980, volume III, part 1, 54-71), then vastness takes on a different form and gives rise to a different kind of space. The direction can be of one of four types. We call it the space of lived-bodily directedness with respect to the first three types, and the space of location with respect to the last one.

Breathing in and out is an example of the first type. A second type is exemplified when handling tools. Here we touch upon the bodily dimension on which Gooding has placed a special emphasis in his reflection on the bodily component of thought experiments. As we have argued in the previous sections, phenomenologically speaking, Gooding is mistaken when locating this bodily dimension outside of the space of lived-bodily directedness. Gooding's mistake is a result of the fact that the second type of directedness is such that its origin is not noticeable to the lived-body directly. It requires mediation through an interaction between body and extra-bodily objects. Yet, it is still the space of lived-bodily directedness that is involved here - not the physical space in which the physical body has a well-defined location in terms of relative position. A third type of directedness relates to the overlap between the lived-body and the physical-body and has rudimentary geometrical characteristics, resulting from an interplay of right/left, up/down, following the position of the physical body. It is still the space of lived-bodily directedness that is involved here.

Finally, a fourth type of directedness and thus space culminates in a cluster of spaceconceptions which is very different from the previous three: take, for instance, the geographical northsouth or Euclidean space. In these examples, vastness has lost its relation to the lived body and takes on the space of what we call the space of location. This is to say that, unlike in the previous three cases, this conception of space does not place the lived body at the "zero point of orientation". As particularly Husserl has shown in his last major publication, the Crisis (Husserl 1970), the theoretical accomplishment of a scientific space-conception which does not imply any reference to the lived body was constitutive for the development of modern science. However, according to Husserl, it is also crucial to keep in mind that such a conception of space is an idealization which in principle cannot be experienced by any embodied subject. Or, to put it differently: just as we can think about geometrical objects like ideal circles, embodied subjects can think about conceptions of space which are detached from any reference to the lived body. Yet, for embodied subjects, neither ideal circles nor bodiless spaces can be directly given without the mediation of a particular theory. From the phenomenological perspective one could say, therefore, that naturalistic programs with respect to space in philosophy of 
science have gained plausibility only because the space of lived-bodily directedness and the space of location were theoretically misunderstood. The above-described directedness is either described along the lines of the space of location, or it is presupposed that the space of location is prior to the space of lived-bodily directedness. In each case a naturalistic program can gain plausibility, implying that the bodily component of (thought) experiments about space must be explained exclusively in terms of standards of familiarity with objects and proper procedures in the space of location. The situation changes if we employ the sketched phenomenology of space to characterize the bodily component of thought experimenting with which Gooding is justly concerned.

\section{On How to Relate Different Types of Space}

As we have seen in the preceding sections, phenomenologists argue that a particular conception of space is the condition of the possibility of the givenness of physical things. Whenever we interact with our natural surroundings, a basic acquaintance with certain characteristics of spatiality is always already presupposed. On a phenomenological view, however, the most fundamental conception of primordial space is not formal as it is, for instance, in Kant. In analyzing the "How" of the givenness of physical things, essential characteristics of spatiality can be intuitively described. Furthermore, it is possible to show how these essential characteristics are related to bodily phenomena like kinaesthetic movements. To put it in a nutshell: From a phenomenological perspective, the notions of subjectivity, embodiment and primordial space are not only inextricably related; they are also equally fundamental if we are to ask for the necessary conditions of our natural world-involvement. In Schmitz, as we have seen, this is the case because subjectivity is a function of bodiliness which in turn is a function of counteracting tendencies towards vastness and narrowness. Yet, if all this is true, two problematic aspects of Newton's thought experiment can be pointed out. This is one way to paradigmatically illustrate of how to assess the quality of a thought experiment from a phenomenological point of view.

First, if space is properly described as a necessary condition of the possibility of the givenness of natural objects, how can some of these objects - namely a water bucket and a rope - stand in a causal relationship with something that is the necessary condition of the very givenness of these objects? Phenomenologically construed, the assumption that a causal relation of this kind exists is a conflation of two different levels of analysis; it is a conflation of phenomena which are to be analyzed within the natural attitude and phenomena whose proper analysis requires the methodologically motivated abandonment of all those presuppositions which are usually constitutive for natural interactions with the world.

Second, and more importantly-however we judge the theoretical merits of Newton's bucket both from a systematic and a historical point of view-Newton's conception of absolute space certainly is a result of the fourth type of directedness and thus belongs to the above mentioned cluster of idealized space-conceptions which are characterized by their detachment from the lived body. Now, the genuinely phenomenological point of a critique of Newton's bucket experiment is that it does not pay appropriate attention to the kind of relationship this thought experiment establishes between the livedbody space - which, as we have argued, is the condition of the possibility of the givenness of familiar objects like water buckets and ropes - and scientific space which, as we have also tried to show, transcends the sphere of that which can be subject to an experience of the lived body. The apparent persuasiveness of Newton's thought experiment stems from the ease with which it seems to make the acceptance of absolute space inevitable due to the familiarity of objects and procedures. This is also the point of Gooding's approach. However, on a closer phenomenological look, we are also led to this conclusion because Newton's thought experiment seems to involve two conceptions of space which are categorically distinct: While the imagination of familiar objects like water buckets and ropes clearly presupposes a basic acquaintance with lived-body space, Newton's absolute space is a theoretical conception which in principle transcends the first-person-perspective of embodied subjects. On this view, then, the error of Newton's thought experiment is to import a theoretical artifact into an 
arrangement of worldly objects without paying attention to the noetic differences between particular conceptions of scientific and extra-scientific space.

\section{Conclusion}

Of course, much more remains to be said about Newton's thought experiment in particular, and a phenomenological approach to thought experiments in general. Our critical discussion of Newton's bucket could turn out shortsighted in the light of claims that this thought experiment has nothing to do with absolute space (see Laymon 1978). At this time we are confident that these claims do not affect our analysis negatively. Moreover, it might be that more steadfastly "processural" phenomenological approaches in the spirit of Sheets-Johnstone reach deeper than our phenomenological discussion. But "deeper" does not mean "more true", and it is very unlikely that it will invalidate our criticisms of Gooding's naturalistic view on the bodily component of thought experiments. It is also likely that we have missed in our explorations the way in which the social realm influences the lived body. In fact this is indeed a problem as far as Schmitz' phenomenology is concerned. But soft-spots like this can only encourage further discussion on the importance of the body in thought experiments, and thereby include the work of Gail Weiss, Judith Butler, and others, to get hold of the social dimension of the lived body.

We hope some basic tenets of a possible phenomenological contribution to the ongoing debate have become clear. From a phenomenological perspective, our natural interactions with the world are mediated by various natural attitudes which in turn consist of a number of typically unquestioned presuppositions. While some of these presuppositions are highly contingent, some others qualify as necessary conditions of the possibility of our natural world-involvement. Certain general characteristics of embodiment and spatiality belong, as we have tried to indicate, to the latter group. Since phenomenologists are predominantly concerned with the analysis of implicit presuppositions of this kind, phenomenological methodology could be, we believe, of considerable importance for the philosophical understanding of thought experiments. While more detailed analyses will be necessary in order to justify this general claim, our aim in this paper was to show that the phenomenological elucidation of the relations between the lived body and primordial space can lend additional, nonnaturalistic support to contemporary "hands over heads" approaches. We agree with Gooding that the principle of "head over heads" is misleading. Yet, as we have shown, Gooding's "hands" are part of the lived body. A naturalistic account of "hands over heads" must therefore fall short.

\section{References}

Brown, James R. The Laboratory of the Mind: Thought Experiments in the Natural Sciences. New York: London: Routledge, 2011. $2^{\text {nd }}$ Edition.

Buzzoni, Marco. Thought Experiment in the Natural Sciences. An Operational and ReflexiveTranscendental Conception. Würzburg: Königshausen \& Neumann 2008.

Froese, Tom and Gallagher, Shaun. "Phenomenology and Artifical Life: Toward a Technological Supplementation of Phenomenological Methodology." Husserl Studies, 26 (2010): 83106.

Gooding, David C. "What is Experimental About Thought Experiments?". Proceedings of the Philosophy of Science Association 2 (1993): 280-290.

Gooding, David C. "The Procedural Turn; or, Why Do Thought Experiments work?", in Cognitive Models of Science, ed. by Ronald N. Giere, 45-76, Minneapolis: University of Minnesota Press, 1992. 
Gooding, David C. Experimenting and the Making of Meaning, Dordrecht: Kluwer Academic Publishers, 1990.

Hammer, Felix. Leib und Geschlecht. Philosophische Perspektiven von Nietzsche bis MerlauPonty und Phänomenologisch-Systematischer Aufriß. Bonn: Bouvier, 1974.

Horowitz, Tamara and Massey, Gerald (eds.). Thought Experiments in Science and Philosophy. Lanham: Rowman \& Littlefield, 1991.

Husserl, Edmund. Cartesian Meditations. An Introduction to Phenomenology. Translated by Dorion Cairns. The Hague: Martinus Nijhoff 1960.

Husserl, Edmund. Phänomenologische Psychologie. Vorlesungen Sommersemester. Edited by Walter Biemel. The Hague: Martinus Nijhoff 1968.

Husserl, Edmund. The Crisis of the European Sciences and Transcendental Phenomenology. An Introduction to Phenomenological Philosophy. Translated by David Carr. Evanston: Northwestern University Press 1970.

Husserl, Edmund. Ideas Pertaining to a Pure Phenomenology and to a Phenomenological Philosophy. First Book. General Introduction to a Pure Phenomenology. Translated by Fred Kersten. The Hague: Martinus Nijhoff, 1983.

Husserl, Edmund. Ideas Pertaining to a Pure Phenomenology and to a Phenomenological Philosophy. Second Book. Studies in the Phenomenology of Constitution. Translated by Richard Rojcewicz and André Schuwer. Dordrecht: Kluwer 1989.

Ierodiakonou, Katerina. "Ancient Thought Experiments: A First Approach." Ancient Philosophy 25 (2005): 125-140.

Kalin, Martin G. "Kant's Transcendental Arguments as Gedankenexperimente." Kant-Studien 63 (1972): 315-328.

Kant, Immanuel. Critique of Pure Reason. Translated and edited by Paul Guyer and Allen W. Wood. Cambridge: Cambridge University Press, 1998.

Kühne, Ulrich. Die Methode des Gedankenexperiments. Frankfurt am Main: Suhrkamp, 2005.

Kujundzic, Nebojsa. "The Role of Variation in Thought Experiments." International Studies in the Philosophy of Science 12 (1998): 239-243.

Laymon, Raymond. "Newton's Bucket.” Journal of the History of Philosophy, 16 (1978): 399413.

Lotz, Christian. From Affectivity to Subjectivity: Husserl's Phenomenology Revisited. Hampshire, 2007.

Mach, Ernst. "Über Gedankenexperimente.” Zeitschrift für den physikalischen und chemischen Unterricht 10 (1897): 1-5.

Mach, Ernst. "Über Gedankenexperimente." in Erkenntnis und Irrtum, by Ernst Mach, 181-197. Leipzig: Verlag von Johann Ambrosius Barth. In translation: Knowledge and Error, translated by J. McCormack, 134-147, Dordrecht: Reidel, 1905.

Moran, Dermot. "Husserl's transcendental philosophy and the critique of naturalism." Continental Philosophy Review 41 (2008): 401-425.

Mohanty, J. N. "The Method of Imaginative Variation in Phenomenology." in Thought Experiments in Science and Philosophy, ed. by in: Tamara Horowitz and Gerald Massey, 261-272. Savage, 1991.

Myers, Mason C. “Analytical Thought Experiments.” Metaphilosophy 17 (1986): 109-118.

Norton, John. "Are Thought Experiments Just What You Thought?" Canadian Journal of Philosophy 26 (1996): 333-366.

Newton, Isaac. The Mathematical Principles of Natural Philosophy. Reprinted in On the Shoulders of Giants, ed. by Stephen Hawking, 733-1160. Philadelphia; Leipzig: Running Press. 
Ørsted, Hans Christian. "First Introduction to General Physics: A Prospectus of Lectures in this Science." In: Selected Scientific Works of Hans Christian Ørsted, 282-309. Translated and edited by Karen Jelved, Andrews D. Jackson, and Ole Knudsen. Princeton: Princeton University Press, $1998[1811]$.

Ørsted, Hans Christian. "Første Indledning til den almindelige Naturlaere." Reprinted in: Naturvidenskabelige Skrifter, 155-190. Kopenhagen: Andr. Fred. Host \& Son, Volume III, 1920[1811].

Reichenbach, Hans. The Philosophy of Space and Time, translated by Maria Reichenbach and John Freud. New York: Dover Publications, Inc., 1958.

Robb, Alfred. The Absolute Relations of Space and Time. Cambridge: Cambridge University Press, 1921.

Schmitz, Hermann. System der Philosophie. 5 volumes (in 10 parts). Bonn: Bouvier, 19641980.

Schmitz, Hermann. Neue Phänomenologie. Bonn: Bouvier, 1980.

Sheets-Johnstone, Maxine. The Primacy of Movement. Philadelphia: John Benjamins, 2000.

Sklar, Lawrence. "I'd Love to be Be a Naturalist - if Only I Knew What Naturalism Was." Philosophy of Science 77 (2010): 1121-1137.

Sorensen, Roy A. Thought Experiments. Oxford: Oxford University Press, 1992.

Welton, Donn (ed.). The Body. Classic and Contemporary Readings. Oxford: Blackwell, 1999.

Zahavi, Dan. "Husserl's Phenomenology of the Body." Études Phénoménologiques 19 (1994): 63-84. 